Ann. Biol. anim. Bioch. Biophys., 1978, 18 (3), 711-716

\title{
Quantitative analysis and measurement of myoelectrical spike activity at the gastroduodenal junction
}

\author{
par A. LATOUR
}

Laboratoire de Physiologie, Ecole Nationale Vétérinaire, 31076 Toulouse Cedex, France

\begin{abstract}
Summary. As a preliminary to the integration of spike activity, slow waves were eliminated by high band-pass filtering when analyzing myoelectrical activity in the small intestine of herbivores and carnivores. This technique, however, could not be applied to the carnivore antrum where the frequency and amplitude of the slow waves were unsuitable. This reports describes a circuit for eliminating the slow waves from the electrical record before measuring the action potentials occurring as spike bursts at the antral level. The slow waves were detected with a trigger. The output signal was obtained from a window circuit having a delay equivalent to the duration of the slow wave and a gate function of maximal spike burst duration. Using an integrator, spiking activity was then plotted at 20-sec intervals on the $y$-axis of a potentiometric recorder, as described in a previous study (Latour, 1973). Slow wave frequency was analyzed by measuring the intervals between triggering with a tachymeter. A pattern of cyclic antral activity was found in dogs.
\end{abstract}

Small intestinal myœlectrical spike activity recorded with chronic implanted bipolar serosal electrodes is easily quantified using a conventional linear integrator (Latour, 1973) connected to an RC 3-stage amplifier. However, integrated values for spike activity are distorted by slow waves. In the intestine, slow-wave activity is easily eliminated by high-pass filtering. This cannot be done in the antrum without removing some spike activity since the slope of the ascending part of antral slow waves is similar to that of some antral spikes. Moreover, the amplitude of the antral slow wave is such that if integrated, it masks changing patterns of spike activity. Thus, when analyzing antral and spike interaction in sheep and dogs (Ruckebusch, 1975), the large amplitude signals (slow waves) must be removed and the small ones (spikes) retained. The circuit described in this paper has been used in the laboratory for more than 2 years for the selective summation of antral spiking activity. The circuit utilizes the constancy of phase-locking antral spike bursts to slow waves - spike bursts occur within 0.5 to $3 \mathrm{sec}$ after the return to the slow wave isoelectric line - to create a window phase locked to the slow wave through which signals may be passed to a conventional linear integrator. The position of the window is fixed by the positive deflection of the slow wave which serves as a trigger for a delay circuit. Characteristics of the integrator, and especially its excellent linearity for samples taken every $20 \mathrm{sec}$, have been previously described (Latour, 1973) and will be used here without any pecularities after slow-wave suppression. 
Design of the circuit.

Electrical activity is recorded from pairs of $\mathrm{Ni} / \mathrm{Cr}$ electrodes anchored in the muscle layers of the antrum and connected to a polygraph (Reega VIII, Alvar, Paris). The signals are preamplified with a time constant of $0.3 \mathrm{sec}$ by the polygraph to $\pm 3 \mathrm{mV}$ monitored at the auxilliary output. After a first stage of amplification (fig. 1), the signals are applied to a triggering system using an operational amplifier (LM 741). The threshold of the trigger is adjusted (peak to peak values of $15 \mathrm{mV}$ ) by a potentiometer depending on the slow-wave amplitude and time course (slope).

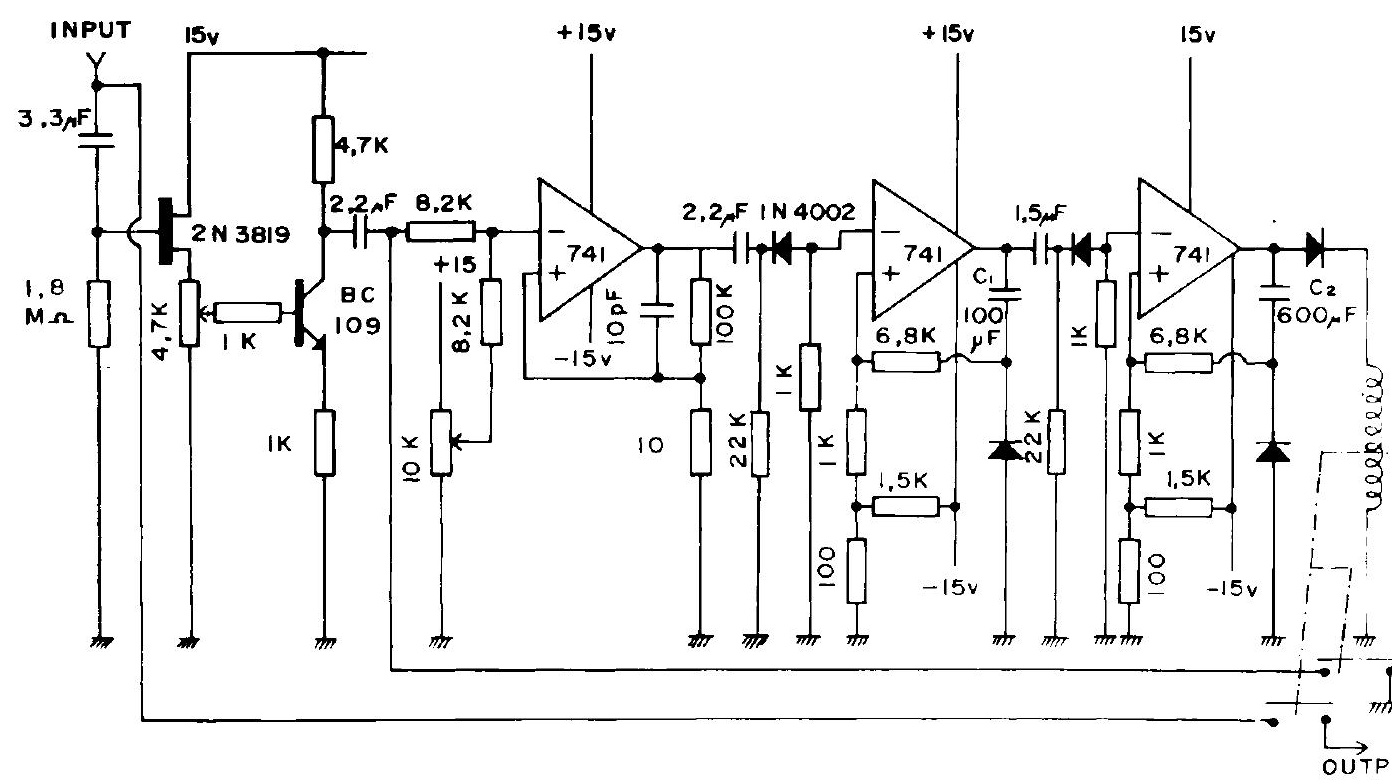

FIG. 1. - Circuit diagram for suppressing slow waves.

The output, a brief square-wave dc. signal, is injected into the delay circuit delivering a constant amplitude pulse, the duration of which depends on the value of $C_{1}$ (fig. 1). The pulse is then differentiated by an R-C circuit, rectified by a diode and fed into another delay circuit (gating circuit). The duration of the $30 \mathrm{~V}$ output signal is adjusted by a capacity $\left(C_{2}\right)$.

The spike activity is obtained through this relay which then blocks the amplifier. The pulse of the "gating circuit" drives the cutting relay of the output signal. This avoids any possibility of triggering by a spike (fig. 2 ).

\section{Operation.}

1) Adjustment of trigger level. - The level chosen for detecting the slow waves has to be higher than that of the mean amplitude of spiking activity. The greater difference in amplitude between the slow waves and spike bursts in dogs thus makes detection easier in this species than in sheep. 


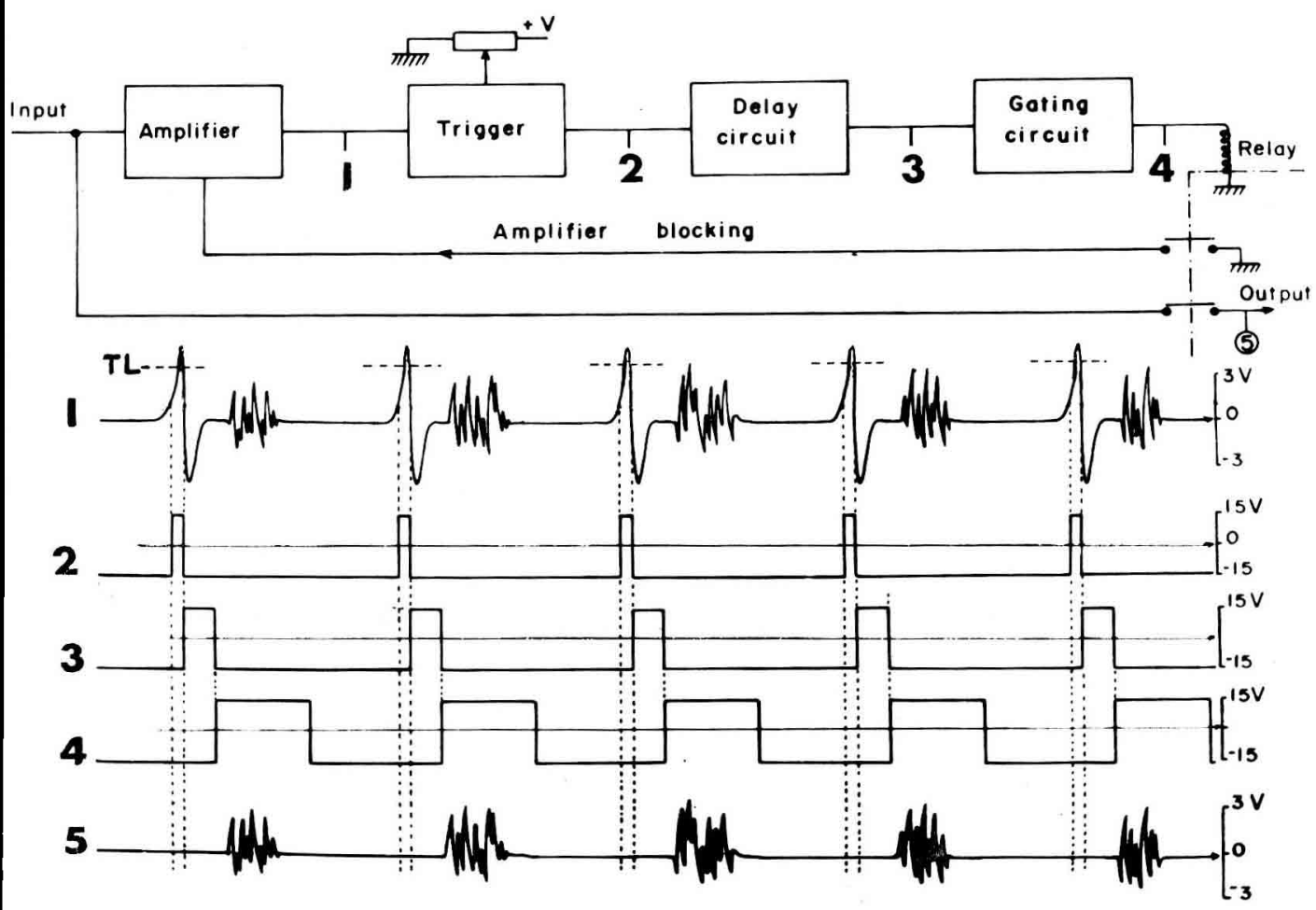

FIG. 2. - Schematic diagram of circuit operation (2-4) for recording antral electrical activity (1). Output signal (5).

2) Choice of delay value. - The duration of signal cutting is adjusted with a minimum elapsed time between the end of the slow wave and the beginning of a possible spike burst (delay 1 ). The possible minimal cutting times from 0.1 to $1 \mathrm{sec}$ make the choice of the value of the capacity $\left(C_{1}\right)$ difficult. For each circuit a diagram of time values in relation to $C_{1}$ is established and a suitable empirical value of $C_{1}$ is selected graphically accordingly to the duration chosen for delay 1 .

3) Duration of output. - This value (delay 2) is determined in relation to the duration of both spike bursts and slow-wave frequency. The statistically more adaptable duration of delay 2 is obtained from the mean values of spike burst duration $\left(t_{s}\right)$ and slow wave interval $(T)$ following the relation :

$$
\text { delay } 2=\frac{\left(\mathrm{t}_{\mathrm{s}}+\mathrm{T}\right)}{1.7}
$$

1.7 is chosen in place of 2 , taking into account the relative stability of $T$ compared with $t_{s}$ to obtain the minimal probability of errors. The delay 2 was not shortened to $\frac{t_{\mathrm{s}}+\mathrm{T}}{2}$ because some prolonged spike bursts might have been eliminated (about 5 p. 100).

The value of $C_{2}$ was graphically determined using the experimental curve of delay $2=f\left(C_{2}\right)$. 


\section{Results.}

In the dog, the electrical activity of the antrum, recorded from a group of electrodes $2 \mathrm{~mm}$ apart fixed on the great curvature of the antrum at $4 \mathrm{~cm}$ from the pylorus, has the following characteristics :

- slow-wave frequency : $6,41 \pm 0.31$ per min.,

- duration of spike bursts : $3.59 \pm 1.20 \mathrm{sec}$.
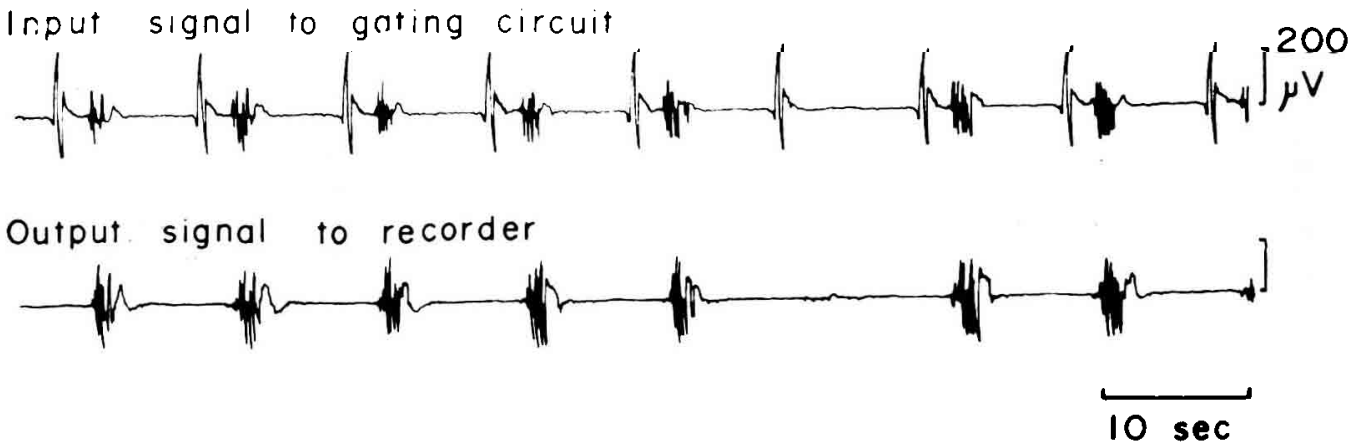

FIG. 3. - (Above.) Direct recording of the electrical activity of canine antrum muscle layers showing slow waves and spike bursts. (Below.) The same record after elimination of the slow waves.

Figure 3 shows both the signals before (above) and after (below) elimination of the slow wave using the respective values of 0.4 and $4.5 \mathrm{sec}$. for delays 1 and 2 corresponding to 100 and 600 microfarads for $C_{1}$ and $C_{2}$. From the diagrammatic configuration (fig. 2), it is obvious that the signal obtained at the end of the trigger stage and normally entering the delay circuit can be used for continuously monitoring the slowwave frequency. This type of detection might be useful for studying the cyclic pattern of the basic electrical rhythm.

The discontinuous output signal (signal 5 in the diagrammatic configuration, fig. 2) represents the spiking activity after elimination of the slow waves. Its value is obtained via a conventional integrator circuit. Figure 4 shows the potentiometric record of the antral spiking activity summed at $20-\mathrm{sec}$ intervals selected by a highpass filter $(F=0.5 \mathrm{~Hz}$ at $-3 \mathrm{~dB})$ using the technique already described (upper panel) and after elimination of the slow waves with the auxilliary circuit described here (middle panel). A typical cyclic pattern of antral spiking activity related to the cyclic activity of the duodenum (lower panel) has been found.

\section{Discussion.}

The two traces of the integrated record presented in figure 4 show clearly that active high-pass filters are suitable when the amplitude and frequency of the slow waves is low, as in the duodenum, but they were unable to discriminate spike activity in the antrum. By contrast, when the values of spiking activity are not impaired by the slow wave, summation demonstrates the lack of spike bursts at the onset of the phase 
pointe. Le dispositif préconisé consiste en une détection préalable de chaque onde lente avec fenêtre d'ouverture pour la sortie des seules salves de potentiels. Leur sommation est alors assurée de 20 en 20 s sur l'axe des y d'un enregistreur potentiométrique selon un procédé déjà décrit (Latour ,1973). La fréquence des ondes lentes est obtenue par tachymétrie à partir des signaux de détection des ondes lentes. L'emploi de ce procédé met en évidence l'existence d'une activité électrique cyclique au niveau de l'antrum chez le chien.

\section{References}

LATOUR A., 1973. Un dispositif simple d'analyse quantitative de l'électromyogramme intestinal chronique. Ann. Rech. vétér., 4, 347-353.

RUCKEBUSCH Y., 1975. Interaction of duodenal and antral activity in sheep and dogs. J. Physiol., Lond., 254, 79-80 P.

RUCKEBUSCH Y., BUENO L., 1975. Electrical activity of the ovine jejunum and changes due to disturbances. Am. J. dig. Dis., 20, 1027-1035.

TIEDEMAN J. S., ARONSON R. S., STRAUSS H. C., 1975. A circuit for measuring maximum negative positive potentials. J. appl. Physiol., 38, 760-762.

WINGATE D., BARNETT T., GREEN R., ARMSTRONG-JAMES M., 1977. Automated high-speed analysis of gastrointestinal myoelectric activity. Am. J. dig. Dis., 22, 243-251. 